\title{
Correction to: High-yield production of L-serine from glycerol by engineered Escherichia coli
}

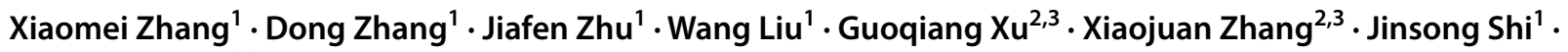 \\ Zhenghong $\mathrm{Xu}^{2,3}$
}

Published online: 26 April 2019

(c) Society for Industrial Microbiology and Biotechnology 2019

\section{Correction to: \\ Journal of Industrial Microbiology \& Biotechnology (2019) 46:221-230 \\ https://doi.org/10.1007/s10295-018-2113-6}

Unfortunately, the order of the Figs. 1-4 has been positioned wrongly in the print published article. Following are the corrections: Fig. 1 of this article should be placed in the position of Fig. 2, Fig. 2 should be placed in the position of Fig. 3, Fig. 3 should be placed in the position of Fig. 4, and Fig. 4 should be placed in the position of Fig. 1. The correct figures (Figs. 1, 2, 3, 4) are given below.

Publisher's Note Springer Nature remains neutral with regard to jurisdictional claims in published maps and institutional affiliations.

The original article can be found online at https://doi.org/10.1007/ s10295-018-2113-6.

Zhenghong Xu

zhenghxu@jiangnan.edu.cn

1 Laboratory of Pharmaceutical Engineering, School of Pharmaceutics Science, Jiangnan University, Wuxi, People's Republic of China

2 National Engineering Laboratory for Cereal Fermentation Technology, Jiangnan University, Wuxi 214122,

People's Republic of China

3 The Key Laboratory of Industrial Biotechnology, Ministry of Education, School of Biotechnology, Jiangnan University, Wuxi, People's Republic of China 


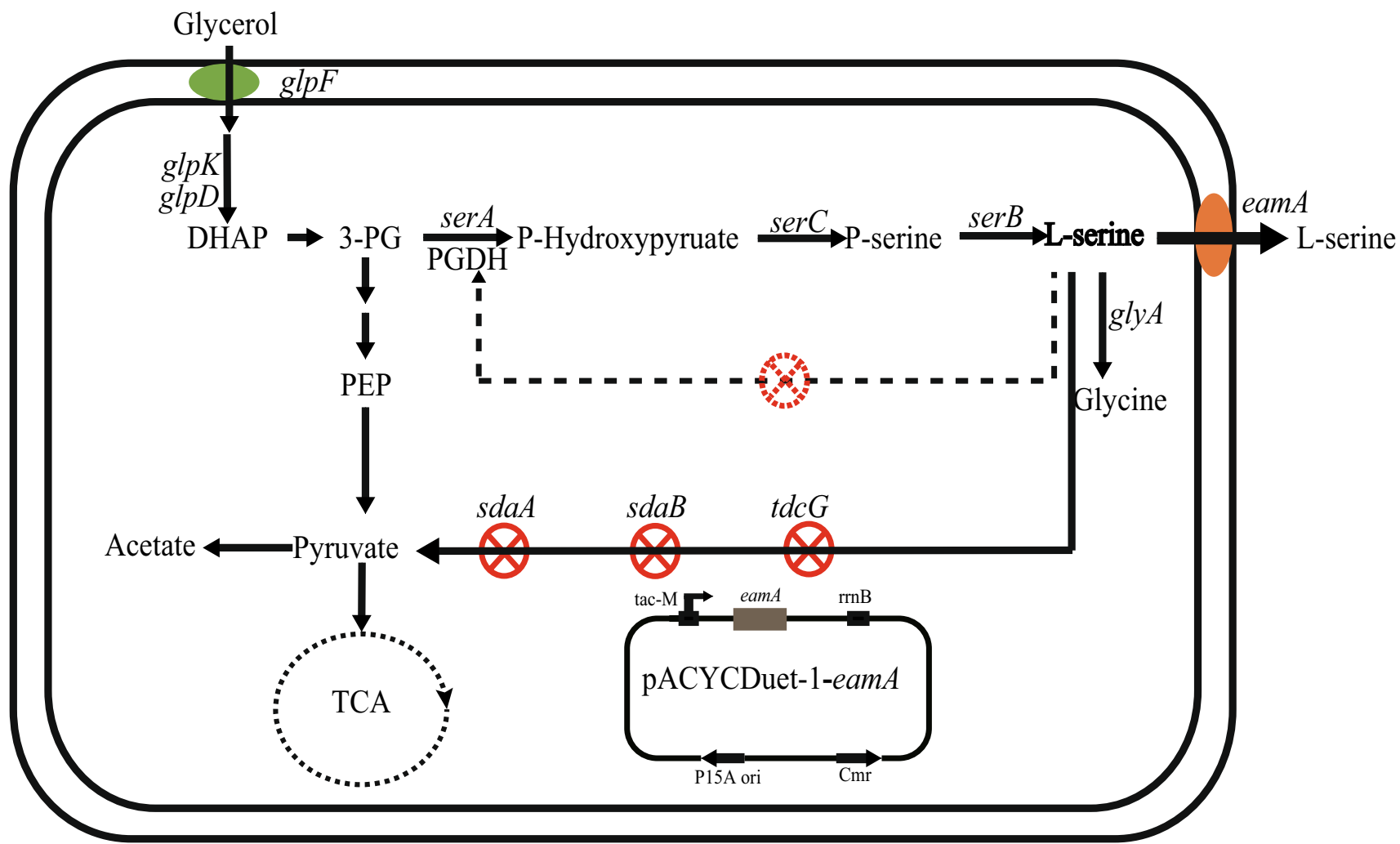

Fig. 1 L-serine biosynthesis pathways from glycerol in E. coli. Genes and enzymes: glycerol facilitator $(g l p F)$; glycerol kinase $(g l p K)$; glycerol 3-phosphate dehydrogenase ( $g l p D)$; 3-phosphoglycerate dehydrogenase (serA); phosphoserine aminotransferase ( $\operatorname{ser} C)$; phosphoserine phosphatase ( $\operatorname{ser} B)$; cysteine/acetyl serine transporter (eamA); serine hydroxymethyltransferase $(g l y A)$; L-serine deaminases ( $s d a A, s d a B$, and $t d c G$ ). Intermediates: dihydroxyacetone phosphate (DHAP); phosphoenolpyruvate (PEP); tricarboxylic acid cycle (TCA). Highlighted arrows indicate pathways in which genes were upregulated by overexpression eamA. Red crosses on solid lines $(\otimes)$ indicate genes that were deleted. Crosses on dashed lines $(G)$ indicate the removal of feedback inhibition (color figure online) 

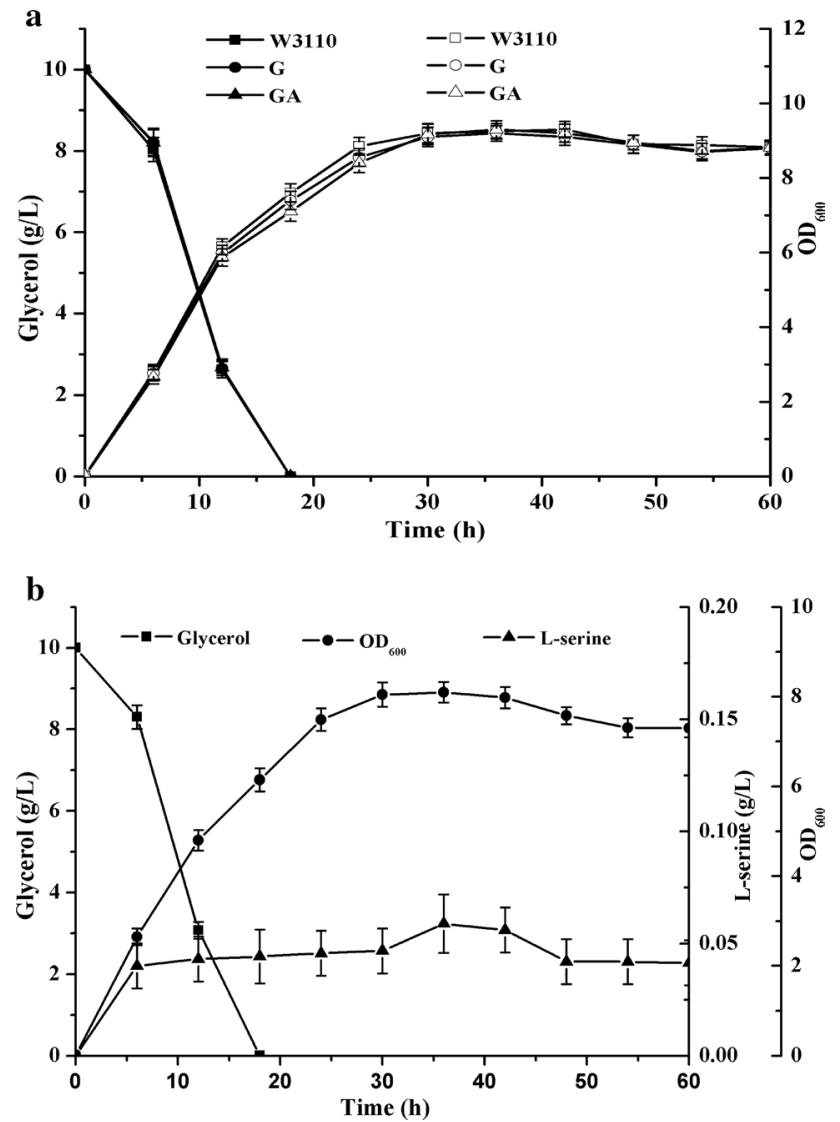

Fig. 2 Comparison of glycerol consumption, cell growth, and L-serine production of strains W3110, G, GA and GAA. a Profiles of residual glycerol and cell density with strains W3110, G, and GA. Squares represent $\mathrm{W} 3110$, circles represent $\mathrm{G}$, triangles represent $\mathrm{GA}$, open symbols represent $\mathrm{OD}_{600}$, closed symbols represent residual glycerol. b Profiles of glycerol consumption, cell growth and L-serine production in GAA. Squares represent residual glycerol, circles represent cell growth, triangles represent L-serine. Values denote the average of three independent experiments, and error bars indicate standard deviation

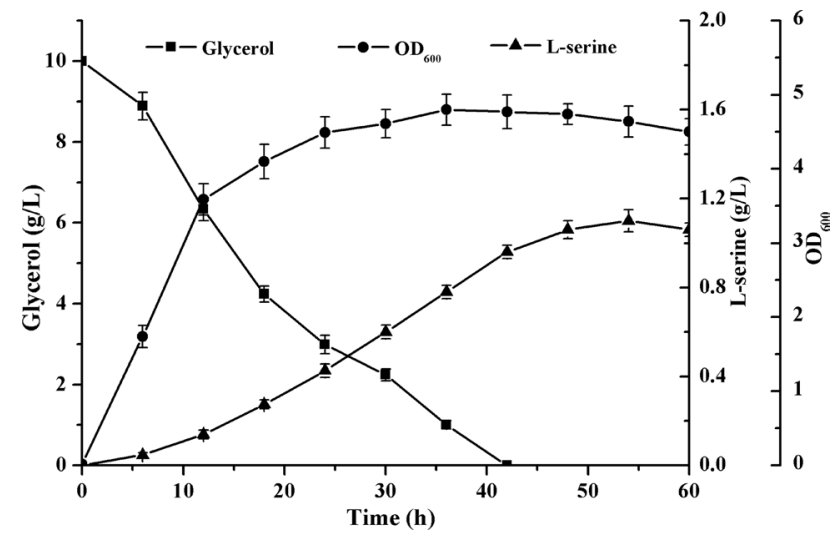

Fig. 3 Time course of L-serine production in the $4 \mathrm{~W}$ strain during batch fermentation. Squares represent residual glycerol, circles represent cell growth, triangles represent L-serine. Values denote the average of three independent experiments, and error bars indicate standard deviation
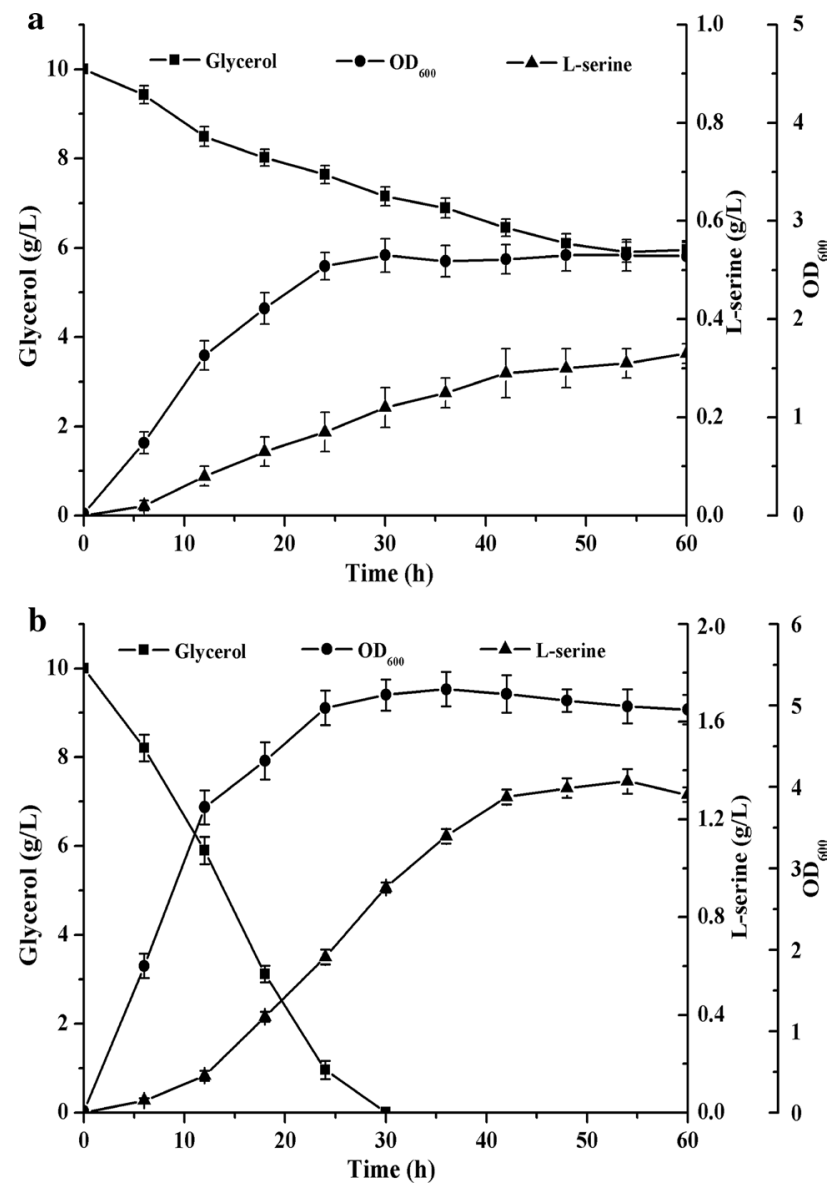

Fig. 4 Comparison of glycerol consumption, cell growth and L-serine production in strains $4 \mathrm{~W}-g l p D-g l p K$ and $4 \mathrm{WA}$. a Profiles of $4 \mathrm{~W}-g l p D-g l p K$. b Profiles $4 \mathrm{WA}$. Squares represent residual glycerol, circles represent cell growth, triangles represent L-serine. Values denote the average of three independent experiments, and error bars indicate standard deviation 